\title{
CHANGES IN AIR QUALITY AND ITS EFFECT ON EMERGENCY ADMISSIONS
}

\author{
Hacer Hicran Mutlu ${ }^{1} \odot$, Kurtulus Aciksari ${ }^{2} \odot$ \\ ${ }^{1}$ Family Medicine Department, Istanbul Medeniyet University, Istanbul, Turkey \\ ${ }^{2}$ Emergency Medicine Department, Istanbul Medeniyet University, Istanbul, Turkey
}

\begin{abstract}
INTRODUCTION: Air pollution is an emerging problem in developing countries as well as the world. Effects of air pollution due to short-term exposure may lead to increase in daily mortality, respiratory and cardiovascular hospital admissions, respiratory and cardiovascular emergency room admissions, respiratory and cardiovascular primary care visits and acute respiratory symptoms. The objective of our study was to examine the relationship between air pollution and diagnoses of patients in family medicine outpatient clinic located in emergency room.
\end{abstract}

MATERIAL AND METHODS: Our study enrolled 17869 patients who were admitted to the family practice outpatient clinic implemented in emergency department. The relationship between patients' diagnosis and air quality was examined.

RESULTS: The genders of the patients were $50.8 \%$ female $(n=9077)$ and $49.2 \%$ male $(n=8792)$. The mean age was $43.9 \pm 19.9$. Respiratory system diagnosis showed a statistically significant relationship with the air quality measurement of PM10 $(p<0.05)$. Patients diagnosed with upper respiratory tract disease and fatigue and hypertension on sensitive air days were found to be significantly higher than those with good air quality. There was a statistical significance between air temperature, and fatigue and cough complaints $(p<0.05)$.

CONCLUSIONS: For human health protection, continuity of life, and environmental sustainability, air pollution should be reduced and brought under control. In our study, with the increase of particulate matter, we observed that patients with respiratory system diseases, fatigue complaints, and hypertension increased. Sharing these results with province-wide authorities may help the settlement and industrial planning in the upcoming years.

KEY WORDS: air pollution, emergency admission, family medicine

Disaster Emerg Med J 2020; 5(4)

\section{INTRODUCTION}

Air pollution is an emerging problem in developing countries as well as the world. Air pollution is related to many factors such as population growth, usage of fossil fuels, industrialization, and increased utilization of vehicles using combustion engines [1] Air pollution can be defined as the rise of chemical substances above certain limits which threatens the wellbeing of living in form of dust, smoke, gas, and vapour. Particulate Matter (PM) 10, which is particularly responsible for air pollution, is a complex mixture of extremely small particles and liquid droplets consisting of acids, organic chemicals, metals, and soil or dust particles. Normally, particles with a particulate matter size greater than $10 \mu \mathrm{m}$ cannot reach alveoli. PM10 value indicates the number of ultrafine particles found in the air that are smaller than $10 \mu \mathrm{m}$. These particles can especially reach the 
alveoli by passing through the airways. The amount of PM10 has been shown to cause cardiovascular and cerebrovascular diseases by activating systemic inflammation and direct and indirect coagulation in the human organism [2].

According to the World Health Organization (WHO) report, outdoor air pollution causes 4.2 million premature deaths annually. $58 \%$ of premature deaths are due to ischemic heart disease and stroke; $18 \%$ are due to chronic obstructive pulmonary disease and acute lower respiratory tract disease, and $6 \%$ are due to lung cancer [3]. Effects of air pollution due to short-term exposure may lead to increase in daily mortality, increase in respiratory and cardiovascular hospital admissions, increase in respiratory and cardiovascular emergency room admissions, increase in respiratory and cardiovascular primary care visits, an increase in acute respiratory symptoms (wheezing, cough, sputum production, respiratory tract infections) [4].

The monitoring of air quality is carried out by both the Ministry of Environment and Urbanization and the weather monitoring stations of some municipalities. At the stations where air quality is mon-

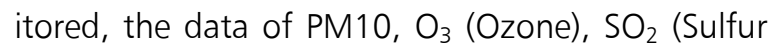
Dioxide), NO (Nitric Oxide), CO (Carbon Monoxide), air temperature, air pressure, and relative humidity are monitored and presented as hourly and daily data. Based on these data, vehicle traffic is the most important NOx source in Europe and it is the primary source of PM10 and the second most important source of PM2.5. In Turkey, with increasing, fossil fuel consumption, particularly for air pollution PM10 parameter; Kahramanmaras, Istanbul, and Ankara are in the top three among air polluted cities [5].

The objective of our study was to examine the relationship between air pollution and diagnoses of patients by studying the relationship between the International Classification of Diseases (ICD)10 data, where the patients admitted to family practice outpatient polyclinics, especially in emergency rooms are diagnosed, and the PM10 and NO values in air quality.

\section{MATERIAL AND METHODS}

Our study enrolled 17869 patients who were admitted to the family practice outpatient clinic implemented in the emergency department of Istanbul Medeniyet University Faculty of Medicine Emergency Depart- ment and whose addresses are in Kadıköy district in Istanbul between May 2017-May 2018. The diagnoses of the patients were retrospectively screened using the ICD-10. In this period, PM10 and NO measurement values of Göztepe Station of the Ministry of Environment and Urbanization were evaluated by considering the 24-hour average data. The relationship between patients' ICD-10 diagnosis codes and air quality was examined. In PM10 evaluation, which is one of the air quality parameters, PM10 0-50 $\mu \mathrm{g} / \mathrm{m} 3$ was characterized as 'Good', 51-100 $\mu \mathrm{g} / \mathrm{m3}$ as 'Medium', $101-260 \mu \mathrm{g} / \mathrm{m3}$ as 'Sensitive', 261-400 $\mu \mathrm{g} / \mathrm{m3}$ as 'Unhealthy', 401$520 \mu \mathrm{g} / \mathrm{m} 3$ as 'Bad', and $>520 \mu \mathrm{g} / \mathrm{m} 3$ as 'Dangerous'. In the European Union member states, while the average limit value of PM10 for 24 hours is $50 \mu \mathrm{g} / \mathrm{m} 3$, the average limit value of $\mathrm{NO}_{2}$ for 24 hours is $200 \mu \mathrm{g} / \mathrm{m3}$ [6]. For the research, authorization was obtained from Istanbul Medeniyet University Faculty of Medicine Ethics Committee in 2019.

\section{Statistical Analysis}

Descriptive values of the data obtained were calculated as mean \pm Standard Deviation (SD), median, number and \% frequency. The suitability of air quality parameters to normal distribution was examined with the Kolmogorov-Smirnov test. The differences between $\mathrm{PM} 10$ and $\mathrm{NO}_{2}$ values, which are among the air quality parameters obtained from the measurement stations, and patient diagnoses were evaluated with the Kruskal Wallis test and the posthoc test was used to determine different measurement values. Statistical significance level was $\mathrm{p}<0.05$ and IBM SPSS (ver. 22.0, Armonk, NY: IBM Corp.) software was used in calculations.

\section{RESULTS}

The genders of the patients who participated in our study were $50.8 \%$ female $(n=9077)$ and $49.2 \%$ male $(n=8792)$. The mean age and SD of our patients were calculated as $43.9 \pm 19.9$. Descriptive values of patient diagnoses and air quality measurement values were calculated (Tab. 1). The diagnoses of patients who were admitted to emergency family practice were examined in terms of air quality measurements PM10 and $\mathrm{NO}_{2}$ (Tab. 2) and it was determined that they did not demonstrate normal distribution. Patients diagnosed with a respiratory system diagnoses showed a statistically signifi- 


\begin{tabular}{l} 
Table 1. Descriptive statistics \\
\hline
\end{tabular}

$\mathrm{CO}_{2}$ - Carbon Dioxide; $\mathrm{NO}_{2}$ - Nitrogen Dioxide; $\mathrm{NOX}_{2}-\mathrm{NADPH}$ oxidase $2 ; \mathrm{O}_{3}-$ Ozone; $\mathrm{PM}$ - Particulate Matter; $\mathrm{SD}$ - Standard Deviation; $\mathrm{SO}_{2}$ - Sulphur dioxide

\begin{tabular}{|c|c|c|c|c|c|c|c|c|}
\hline Diagnosis & PM10 & $\mathrm{n}$ (days) & Median (Min-Max) & $\mathrm{p}$ & $\mathrm{NO}_{2}$ & n (days) & Median (Min-Max) & $p$ \\
\hline \multirow{3}{*}{$\begin{array}{l}\text { J/Diseases of the } \\
\text { Respiratory System }\end{array}$} & $0-50$ & 172 & 35 (4-94) & \multirow[t]{3}{*}{$0.009^{*}$} & $0-100$ & 206 & $36(4-111)$ & \multirow[t]{3}{*}{$0.009 *$} \\
\hline & $51-100$ & 52 & $42(13-111)$ & & $101-120$ & 23 & $45(13-77)$ & \\
\hline & $101-260$ & 27 & $46(23-81)^{*}$ & & $>121$ & 19 & $49(23-81)^{*}$ & \\
\hline \multirow{3}{*}{$\begin{array}{l}\text { M/Diseases of } \\
\text { Musculoskeletal } \\
\text { System }\end{array}$} & $0-50$ & 172 & $14(2-30)$ & \multirow[t]{3}{*}{0.608} & $0-100$ & 206 & $14(2-31)$ & \multirow[t]{3}{*}{0.410} \\
\hline & $51-100$ & 51 & $16(2-40)$ & & $101-120$ & 22 & $17(3-40)$ & \\
\hline & $101-260$ & 27 & $14.5(12-20)$ & & $>121$ & 19 & $15(13-20)$ & \\
\hline \multirow[t]{3}{*}{ R53/Fatigue } & $0-50$ & 140 & $5(1-44)$ & \multirow[t]{3}{*}{$0.005^{*}$} & $0-100$ & 173 & $4(1-44)$ & \multirow[t]{3}{*}{0.095} \\
\hline & $51-100$ & 43 & $3(1-18)^{*}$ & & $101-120$ & 14 & $3(1-18)$ & \\
\hline & $101-260$ & 22 & $2.5(1-23)^{*}$ & & $>121$ & 18 & $3(1-23)$ & \\
\hline \multirow[t]{3}{*}{ R05/Cough } & $0-50$ & 135 & $4.5(1-18)$ & \multirow[t]{3}{*}{0.309} & $0-100$ & 160 & $4(1-18)$ & \multirow[t]{3}{*}{0.686} \\
\hline & $51-100$ & 36 & $3(1-20)$ & & $101-120$ & 16 & $3(1-12)$ & \\
\hline & $101-260$ & 23 & $4(1-11)$ & & $>121$ & 16 & $5(1-20)$ & \\
\hline \multirow[t]{3}{*}{ i10/Hypertension } & $0-50$ & 164 & $2(1-7)$ & \multirow[t]{3}{*}{$0.033^{*}$} & $0-100$ & 199 & $3(1-7)$ & \multirow[t]{3}{*}{0.073} \\
\hline & $51-100$ & 53 & $3(1-7)$ & & $101-120$ & 22 & $2(1-5)$ & \\
\hline & $101-260$ & 25 & $2(1-3)^{*}$ & & $>121$ & 18 & $2(1-3)$ & \\
\hline
\end{tabular}

$\mathrm{NO}_{2}$ - Nitrogen Dioxide; PM — Particulate Matter

cant relationship with the air quality measurement of PM10 $(p<0.05)$. Patients diagnosed with upper respiratory tract disease on sensitive air days were found to be significantly higher than those with good air quality. There was a statistically significant relationship between PM10 and patients diagnosed with fatigue $(p<0.05)$. It was observed that the admissions to the emergency room of the patients diagnosed with fatigue decreased significantly as the weathers quality becomes lower. A statistically significant relationship was found between PM10 and patients diagnosed with hypertension 
$(p<0.05)$. No statistically significant relationship was found between the patients diagnosed with $M(00-99)$. Diseases of the musculoskeletal system and connective tissue and PM10 ( $p>0.05)$. Finally, among the diagnoses that were examined, no significant relationship was found between cough and PM10 ( $p>0.05)$. There was a statistical significance between air temperature, and fatigue and cough complaints $(p<0.05)$. There was no statistical significance between humidity and the complaints. When the diagnoses of the patients are examined in terms of $\mathrm{NO}_{2}$, another parameter used in the evaluation of air quality; a statistically significant relationship was observed in the diagnosis codes of $\mathrm{J}(00-99)$ in terms of respiratory system diseases $(p<0.05)$. As the air quality became more sensitive, the number of patients diagnosed with respiratory system diseases increased significantly in the upper J(00-99) diagnostic codes. No statistically significant relationship was found between the patients diagnosed with $\mathrm{M}(00-99)$ Diseases of the musculoskeletal system and $\mathrm{NO}_{2}(p>0.0 .05)$. Patients with diagnosed with pain, fatigue, cough, and hypertension respectively were not found to be significantly related to the $\mathrm{NO}_{2}$ measurement levels $(p>0.0 .05, p>0.0 .05, p>0,0.05$, and $p>0.05)$.

\section{DISCUSSION}

With the industrial revolution, air pollution has become one of the biggest problems faced in the 19th century, and due to increasing use of fossil fuels and industrialization in our country, it is increasing day by day. Depending on short-term and long-term exposure to air pollution, its effects on human health may vary. Especially after exposure to particulate matter, air pollution has been shown to cause an average decrease of 1-2 years in life expectancy $[7,8]$. It has been shown that exposure to pollutants such as PM and ozone in the air is associated with increased mortality and hospitalizations due to respiratory and cardiovascular diseases [9].

In research studies examining the effects of air pollution on hospital admissions in Europe and the United States of America (USA), it has been shown that, depending on the increase in PM10 levels, the rates of admission to hospital emergency rooms and mortality due to asthma and chronic obstructive pulmonary disease (COPD) in patients aged 65 years and older have increased $[10,11]$. In a study conducted in Seattle, USA, it is shown that every $10 \mu \mathrm{g} / \mathrm{m} 3$ increase in PM10 caused an increase of $13-3.7 \%$ in COPD and asthma patients. In the study conducted in Zonguldak province, a positive and weak relationship was detected between all respiratory diseases and $\mathrm{SO}_{2}$ and $\mathrm{PM} 10$ [12]. In another study conducted in Balikesir province, no relation was found between PM10 levels and respiratory diseases [13]. In our study, we detected that more patients diagnosed with respiratory system diseases were admitted on days when air pollution was intense compared to other days.

In a study conducted in Switzerland, every $10 \mu \mathrm{g} / \mathrm{m} 3$ increase in PM10 caused an increase in symptoms of chronic cough, sputum, and daytime shortness of breath in individuals between the ages of 18 and 60. In our study, we observed that as the PM10 value increased, more patients diagnosed with R 05 'Cough' were not admitted to the emergency service. We consider these patients are evaluated primarily in the emergency higher priority areas and/or have different diagnoses.

In a study conducted in Hong Kong, the effects of air pollutants on COPD exacerbations were investigated, and a significant direct relationship was detected between the hospitalization due to COPD acute exacerbations and increased air content of $\mathrm{SO}_{2}, \mathrm{NO}_{2}, \mathrm{PM} 10$, and PM2.5. High levels of air pollutants increase both the hospitalizations and emergency admissions due to acute exacerbation of COPD [11]. It has been shown that, at times of air pollution, the number of consultations to family physicians for asthma and lower respiratory tract diseases, although not specific for COPD, increased [14].

It has been shown that particulate matter levels are associated with increased systemic inflammation. Especially with increasing PM values, the average values of $C$ reactive Protein (CRP), IL- 6 , and White Blood Count (WBC) increase and this increase has been shown to adversely affect the prognosis of patients with diabetes, obesity, and hypertension [15]. In animal experiments on the effects of air pollution, dogs exposed to particulate matter have been shown to have increased systolic blood pressure, diastolic blood pressure, mean arterial pressure, and increased heart rate [16]. In addition, it has been shown that particulate matter levels are associated with acute peripheral artery narrowing and arterial reactivity by disrupting endothelial function $[17,18]$. In a study conducted in the Republic of China, it was 
shown that every $10 \mu \mathrm{g} / \mathrm{m} 3$ increase in PM values caused an increase in the number of admissions to emergency rooms due to hypertension [19]. In our study, consistently with the literature, we also found that the admissions to green areas of the emergency room due to hypertension increased on days when PM10 was high in the air.

The effect of temperature on human health has been investigated, but the studies on the effect of humidity are somewhat more limited. As a rule of thumb, the adverse effects of relative humidity on human health can be reduced to a minimum level by keeping the humidity between $40 \%$ and $60 \%$; in case of relative humidity above and below these levels, physical discomfort can be encountered. In a study, it was observed that admissions to family practice polyclinics due to respiratory infections increased with increasing humidity levels [20]. In our study, no relationship was found between humidity and the complaints. This may be because patients are climatized due to the constant high humidity in Istanbul.

In the study of Makinen et al. [21], it was stated that low temperature was the cause of recurrent respiratory tract infections. In a retrospective study conducted by Danielides et al. [22], it was shown that cold temperatures increased the incidence of acute laryngitis. In another study, [23] it was shown that in every 1.8 Celsius temperature increase exceeding the seasonal threshold, admissions to the hospital with complaints about respiratory tract diseases increased by $4.5 \%$. In our study, in parallel with the literature, it was observed that with temperature drops, cough and fatigue complaints increased.

\section{RESULTS}

For human health protection, continuity of life, and environmental sustainability, air pollution should be reduced and brought under control. In our study, with the increase of particulate matter, which is one of the air pollution parameters, we observed that patients with respiratory system diseases, fatigue complaints, and hypertension increased. Since $\mathrm{NO}_{2}$ values were much lower than the limit values in the region where we conducted our study, we have only seen an increase in the admissions for respiratory diseases. Sharing these results with province-wide authorities may help the settlement and industrial planning in the upcoming years.

\section{REFERENCES}

1. Kampa $M$, Castanas $E$. Human health effects of air pollution. Environ Pollut. 2008; 151(2): 362-367, doi: 10.1016/j.envpol.2007.06.012, indexed in Pubmed: 17646040.

2. Anderson J0, Thundiyil JG, Stolbach A. Clearing the air: a review of the effects of particulate matter air pollution on human health. J Med Toxicol. 2012; 8(2): 166-175, doi: 10.1007/s13181-011-0203-1, indexed in Pubmed: 22194192.

3. https://www.who.int/health-topics/air-pollution\#tab=tab_1.

4. Zhang X. Particles Matter, Nitrogen Dioxide and Sulfur Dioxide. Current Topics in Environmental Health and Preventive Medicine. 2019: 217-235, doi: 10.1007/978-981-32-9182-9_11.

5. http://www.cmo.org.tr/resimler/ekler/10504079d7e9ced_ek.pdf?tip$\mathrm{i}=72$ \&turu $=$ X\&sube $=0$.

6. Gazete R. Hava Kalitesi Değerlendirme ve Yönetimi Yönetmeliği. Çevre Ve Orman Bakanl. 2008; 26898: 6.

7. Dockery DW, Pope CA, Xu X, et al. An association between air pollution and mortality in six U.S. cities. N Engl J Med. 1993; 329(24): 1753-1759, doi: 10.1056/NEJM199312093292401, indexed in Pubmed: 8179653.

8. Pope CA, Thun MJ, Namboodiri MM, et al. Particulate air pollution as a predictor of mortality in a prospective study of US adults. Am J Respir Crit Care Med. 1995; 151(3): 669-74.

9. Brunekreef $B$, Holgate ST. Air pollution and health. The lancet. 2002; 360(9341): 1233-42.

10. Samet JM, Dominici $F$, Curriero FC, et al. Fine particulate air pollution and mortality in 20 U.S. cities, 1987-1994. N Engl J Med. 2000; 343(24): 1742-1749, doi: 10.1056/NEJM200012143432401, indexed in Pubmed: 11114312.

11. Atkinson RW, Anderson HR, Sunyer J, et al. Acute effects of particulate air pollution on respiratory admissions: results from APHEA 2 project. Air Pollution and Health: a European Approach. Am J Respir Crit Care Med. 2001; 164(10 Pt 1): 1860-1866, doi: 10.1164/ajrccm.164.10.2010138, indexed in Pubmed: 11734437.

12. TAĞIL Ş, Menteşe S. ZONGULDAK'TA HAVA KIRLilïĞi PM10 \& SO2 ILE ILIŞKILI OLARAK SEÇILMIŞ SOLUNUM YOLU HASTALIKLARININ ZAMANSAL VE MEKÂNSAL DEĞişimi1. Balıkesir Üniversitesi Sos Bilim Enstitüsü Derg. 2012; 15(27): 3-18.

13. Tağıl Ş. Balıkesir'de solunum yolu hastalıklarının mekansal dağılışı üzerine etkisini anlamada jeo-istatistik teknikler. ; 2007.

14. Hajat $S$, Haines A, Goubet $S A$, et al. Association of air pollution with daily GP consultations for asthma and other lower respiratory conditions in London. Thorax. 1999; 54(7): 597-605, doi: 10.1136/ thx.54.7.597, indexed in Pubmed: 10377204.

15. Dubowsky SD, Suh H, Schwartz J, et al. Diabetes, obesity, and hypertension may enhance associations between air pollution and markers of systemic inflammation. Environ Health Perspect. 2006; 114(7): 992-998, doi: 10.1289/ehp.8469, indexed in Pubmed: 16835049.

16. Bartoli $C R$, Wellenius $G A$, Diaz $E A$, et al. Mechanisms of inhaled fine particulate air pollution-induced arterial blood pressure changes. 
Environ Health Perspect. 2009; 117(3): 361-366, doi: 10.1289/ ehp.11573, indexed in Pubmed: 19337509.

17. Brook RD, Franklin B, Cascio W, et al. Expert Panel on Population and Prevention Science of the American Heart Association. Air pollution and cardiovascular disease: a statement for healthcare professionals from the Expert Panel on Population and Prevention Science of the American Heart Association. Circulation. 2004; 109(21): 2655-2671, doi: 10.1161/01. CIR.0000128587.30041.C8, indexed in Pubmed: 15173049.

18. O'Neill MS, Veves A, Zanobetti A, et al. Diabetes enhances vulnerability to particulate air pollution-associated impairment in vascular reactivity and endothelial function. Circulation. 2005; 111(22): 2913-2920, doi: 10.1161/CIRCULATIONAHA.104.517110, indexed in Pubmed: 15927967.

19. Guo Y, Tong S, Li S, et al. The relationship between particulate air pollution and emergency hospital visits for hypertension in Beijing, China. Sci Total Environ. 2010; 408(20): 4446-4450, doi: 10.1016/j. scitotenv.2010.06.042, indexed in Pubmed: 20638709.
20. Nastos PT, Matzarakis A. Weather impacts on respiratory infections in Athens, Greece. Int J Biometeorol. 2006; 50(6): 358-369, doi: 10.1007/s00484-006-0031-1, indexed in Pubmed: 16596366.

21. Mäkinen TM, Juvonen $R$, Jokelainen J, et al. Cold temperature and low humidity are associated with increased occurrence of respiratory tract infections. Respir Med. 2009; 103(3): 456-462, doi: 10.1016/j. rmed.2008.09.011, indexed in Pubmed: 18977127.

22. Danielides V, Nousia CS, Patrikakos G, et al. Effect of meteorological parameters on acute laryngitis in adults. Acta Otolaryngol. 2002; 122(6): 655-660, doi: 10.1080/000164802320396358, indexed in Pubmed: 12403130.

23. Michelozzi P, Accetta G, De Sario M, et al. PHEWE Collaborative Group. High temperature and hospitalizations for cardiovascular and respiratory causes in 12 European cities. Am J Respir Crit Care Med. 2009; 179(5): 383-389, doi: 10.1164/rccm.200802-2170C, indexed in Pubmed: 19060232. 